\title{
Comparison of work-related fear-avoidance beliefs across different anatomical locations with musculoskeletal pain
}

This article was published in the following Dove Press journal:

Journal of Pain Research

31 August 201 I

Number of times this article has been viewed

\author{
Corey B Simon' \\ Sandra E Stryker ${ }^{2}$ \\ Steven Z George ${ }^{3}$ \\ 'Department of Physical Therapy, \\ College of Public Health and Health \\ Professions, University of Florida, \\ Gainesville, Florida, USA; ' 2 Life's Work \\ Physical Therapy, Portland, Oregon, \\ USA; ${ }^{3}$ Department of Physical Therapy \\ and Center for Pain Research and \\ Behavioral Health, College of Public \\ Health and Health Professions, \\ University of Florida, Gainesville, \\ Florida, USA
}

Background: The influence of work-related fear-avoidance on pain and function has been consistently reported for patients with musculoskeletal low back pain. Emerging evidence suggests similar influences exist for other anatomical locations of musculoskeletal pain, such as the cervical spine and extremities. However, research is limited in comparing work-related fear-avoidance and associations with clinical outcomes across different anatomical locations. The purpose of this study was to examine the associations between work-related fear-avoidance, gender, and clinical outcomes across four different musculoskeletal pain locations for patients being treated in an outpatient physical therapy setting.

Methods: This study was a secondary analysis of data obtained prospectively from a cohort of 313 participants receiving physical therapy from an outpatient clinic.

Results: No interaction was found between gender and anatomical location of musculoskeletal pain on work-related fear-avoidance scores. Work-related fear-avoidance scores were higher in the cervical group versus the lower extremity group; however, there were no other differences across anatomical locations. Work-related fear-avoidance influenced intake pain intensity in patients with spine pain but not extremity pain. Conversely, work-related fear-avoidance influenced intake function for participants with extremity pain but not spine pain. Similar results were observed for change scores, with higher work-related fear-avoidance being associated with more, not less, change in pain and function for certain anatomical locations.

Conclusion: These findings suggest that work-related fear-avoidance is similar for patients experiencing musculoskeletal pain. However, associations between work-related fear-avoidance and clinical outcomes may differ based on the anatomical location of that pain. Further, increased work-related fear-avoidance may not be indicative of poor clinical outcomes for this type of patient population.

Keywords: gender, fear, avoidance, spine pain, pain intensity, function, musculoskeletal

\section{Introduction}

A critical analysis reported that, in working populations, psychological distress related to low back injury is associated with the persistence of disability, return to work status, and financial burden. ${ }^{1}$ A psychological factor that appears particularly influential is work-related fear-avoidance, whereby an individual exhibits pain-related fear specific to their work beliefs. Relationships between work-related fear-avoidance and clinical outcomes like pain and function are routinely reported for patients experiencing low back pain. Specifically, work-related fear-avoidance beliefs have been found to be predictive of disability, ${ }^{2-4}$ work-related physical capacity, ${ }^{5}$ and return to work status, ${ }^{2,6,7}$ for patients with low back pain.
Correspondence: Corey B Simon; Steven Z George PO Box 100154, UFHSC, Gainesville, FL 32610-0I54, USA

Tel +l 3522736085

Fax: +l 3522736109

Email coreysimon@phhp.ufl.edu; szgeorge@phhp.ufl.edu 
The larger body of knowledge in work-related fear-avoidance pertains to low back pain versus other anatomical locations with musculoskeletal pain (eg, neck pain, extremity pain). This may be partially attributed to frequent use of the low back for validation of fear-avoidance theory ${ }^{8-10}$ and development of fear-avoidance measures. ${ }^{11}$ Nevertheless, emerging evidence suggests that the importance of work-related fear-avoidance may not be exclusive to this anatomical location. Studies analyzing the Fear-Avoidance Beliefs Questionnaire work subscale scores ${ }^{12}$ and individual Fear-Avoidance Beliefs Questionnaire work-subscale screening items ${ }^{13}$ have found no difference in work beliefs for other anatomical locations when compared with the lumbar spine. Further, work-related fear-avoidance beliefs have been associated with pain and disability for patients with other disorders such as mechanical neck pain ${ }^{14}$ and patellofemoral pain. ${ }^{15}$

However, questions remain as to the capacity of work-related fear-avoidance to affect different anatomical locations. For example, research is limited on comparing the strength of association of work-related fear-avoidance with clinical outcomes across multiple pain locations. George et $\mathrm{al}^{12}$ compared fear-avoidance beliefs in patients with neck pain versus low back pain and, although similar raw workrelated fear-avoidance scores by anatomy were reported, a stronger association between work-related fear-avoidance and disability existed in the low back pain cohort. Another issue may be the existence of a gender difference in fear-avoidance beliefs across anatomical locations. Research has suggested that males with neck or low back pain have potential for higher work-related fear-avoidance beliefs compared with females. ${ }^{11,12,16}$ Additionally, association between pain-related psychological constructs (eg, anxiety) and pain reports have been reported to be stronger in males. ${ }^{17}$

Therefore, the purpose of this study was to examine workrelated fear-avoidance beliefs across four different anatomical locations with musculoskeletal pain for patients being treated in an outpatient physical therapy setting. The first aim was to determine whether work-related fear-avoidance differed across cervical, upper extremity, lumbar, and lower extremity locations and analyze potential associations between work-related fear-avoidance beliefs and gender for these anatomical locations. It was hypothesized that (1) consistent with other work in this area, ${ }^{12,13}$ raw scores for fear-avoidance beliefs about work would be similar regardless of anatomical location and (2), consistent with other work in this area, ${ }^{11,12,16}$ males would report higher levels of work-related fear-avoidance than females across anatomical locations. The second aim was to examine whether work-related fear-avoidance had similar influence by anatomical location on pain intensity and function. It was hypothesized that after controlling for selected demographic factors including gender, patients with low back pain would have a stronger relationship between work-related fear-avoidance, pain intensity, and function levels (at intake and represented in change scores), compared with patients with musculoskeletal pain in other anatomical locations. The second aim provided data to determine if findings from a previous cross-sectional study ${ }^{12}$ were consistent with this longitudinal study.

\section{Methods}

Study design

This was a secondary analysis of data from a prospective cohort study ${ }^{18}$ of patients receiving physical therapy for musculoskeletal pain from an outpatient physical therapy clinic. Included in the current analyses are selected data from intake (work-related fear-avoidance, pain intensity, and function) and discharge (pain intensity and function) assessments.

\section{Patients}

A consecutive sample of patients receiving outpatient physical therapy from an outpatient physical therapy clinic in Portland, Oregon, from February 2009 to June 2010 contributed data to this study. Criteria for inclusion in the original prospective study were: being able to both read and speak the English language (for filling out assessment measurements); the existence of musculoskeletal pain, serving as the primary motive for seeking out physical therapy services; successful completion of intake and discharge assessment measurements; and completion of physical therapy services by scheduled completion date of data collection (June 1, 2010).$^{18}$ Criteria for exclusion from the study were: if pain complaints were deemed non-musculoskeletal in origin by the physical therapist; if the patient had multiple sites of musculoskeletal pain (eg, having both neck and low back pain); or if the patient had no pain at the beginning of the study. Data were collected during routine clinical encounters and de-identified before analysis. As such, this study qualified as exempt by the University of Florida Institutional Review Board and patients were not required to provide informed consent.

\section{Measures}

\section{Clinical}

Age, gender, symptom duration, and anatomical location information was collected at intake. Symptom duration was defined as the number of days from the onset of symptoms 
until the patient started physical therapy. Anatomical location of pain was determined by primary patient complaint, which was verified upon initial examination by the physical therapist. Anatomical location of musculoskeletal pain was then collapsed into one of four areas for the purpose of the current analysis: cervical, upper extremity, lumbar, or lower extremity. The authors have used similar approaches for differentiating anatomical location in their previous studies of depressive symptoms ${ }^{19}$ and fear-avoidance of physical activity. ${ }^{18}$

\section{Fear-avoidance beliefs}

The Fear-Avoidance Beliefs Questionnaire (FABQ) was completed during intake. The work subscale (FABQ-W) was the sole fear-avoidance measure included in this analysis as data from the physical activity scale (FABQ-PA) have been previously reported. ${ }^{18}$ The FABQ-W comprise seven items that are scored on a seven-point Likert scale. Answers range from "completely disagree" to "completely agree," with a total score ranging from 0 to 42 . Larger scores on the FABQ-W are indicative of higher levels of work-related fear-avoidance. The FABQ-W was originally intended for patients with low back pain, ${ }^{11}$ and requires slight semantic modification to allow for use in other anatomical locations. An example is replacing five instances of the word "back" on the FABQ-W to "neck" to use in the neck pain cohort. Validation of the modified FABQ-W was not part of this analysis, however prior modification of the FABQ has been shown to have ample predictive validity in previous studies involving musculoskeletal pain. ${ }^{11,14,15,18,20}$

\section{Pain intensity}

Patients completed a visual analog scale (VAS) at intake and discharge. The VAS was implemented to measure pain intensity, which has been found to be a valid and reliable measure of musculoskeletal pain. ${ }^{21}$ The VAS consists of a $10 \mathrm{~cm}$ line anchored by "no pain" and "worst pain imaginable," with participants drawing through the line to indicate present level of pain intensity. The distance the patient marked from the "no pain" anchor was measured and reported as pain intensity to one decimal point.

\section{Function}

The CareConnections Functional Outcomes Index (CCFOI) ${ }^{22}$ (formerly Therapeutic Associates Outcomes System [TAOS]) was used to obtain a self-reported measure of function. It combines five functional activities specific to anatomical location of pain (concentration, headaches, reading, driving, and lifting for cervical spine pain) with five functional activities independent of anatomical location (walking, work, personal care, sleeping, and recreational activities). Functional activities are rated on a scale of 0 (lowest level of function) to 5 (highest level of function). A score for the CCFOI is derived by adding scores for all activities. The final score is reported as a percentage from $0 \%$ to $100 \%$. Currently, there is limited psychometric information pertaining to this measure. ${ }^{23}$ However, the CCFOI was deemed to have face validity and appears responsive based on previous analysis with the FABQ-PA. ${ }^{18}$

\section{Physical therapy practice}

The clinic used for data collection is an outpatient setting specializing in orthopedic manual physical therapy. Four physical therapists were involved in the study (one male, three females). Physical therapists were either fellowship trained or enrolled in an orthopedic manual therapy fellowship program, with the exception of one physical therapist who was preparing for entrance into a fellowship program. One physical therapist was an orthopedic certified specialist through the American Physical Therapy Association. Average clinical experience was 5.8 years (range $=1-13$ years) .

\section{Patient treatment}

Patient treatment was not a primary focus of this analysis and is therefore only summarized. A more thorough description of treatment is provided in a recent study that utilized the same patient cohort. ${ }^{18}$ Prior to receiving the scored FABQ-W from patients, physical therapists were given information regarding the Fear-Avoidance Model and how to interpret FABQ-W scores. Physical therapists were instructed to provide treatment as they normally would for musculoskeletal cases. However, therapists were encouraged to use fear-avoidance management strategies, such as adopting more active interventions for individuals with elevated fear-avoidance beliefs. These general guidelines were used as adjuncts to the professional judgment and clinical reasoning of each physical therapist, which included experience in conceptual methods of neuroplasticity and the treatment of patients with chronic pain. ${ }^{24}$

Treatment consisted of therapeutic exercise (eg, range of motion [ROM], strengthening, motor control retraining), manual therapy (eg, spinal or peripheral joint mobilization, spinal or peripheral manipulative therapy), patient education (eg, postural education, pain modulation strategies, graded exposure techniques, return to work strategies), and/ or modalities. This clinic implemented a "patient-centered" program that was specific to patient needs and accounted for potential fear-avoidance, so no standardized or protocoldriven treatments were provided. 


\section{Data analysis}

Analyses were completed using SPSS Statistics software (v 18.0; IBM corp, Armonk, NY). Alpha level was conservatively set at 0.01 due to the number of planned analyses.

\section{Aim I: gender and anatomical location of musculoskeletal pain}

Differences in work-related fear-avoidance were analyzed using $2 \times 4$ analysis of variance and Bonferroni post hoc testing when appropriate. Effect sizes were computed from estimated marginal means using Cohen's $d$.

\section{Aim 2: pain intensity and function}

In line with our second aim, correlations and regression models were separated for comparison based on anatomical location of musculoskeletal pain as we have done in our previous studies investigating anatomical location. ${ }^{18,19}$ Influence of work-related fear-avoidance on intake pain intensity and function level was first analyzed. A Pearson's Product Moment Correlation was performed to examine simple work-related fear-avoidance by clinical outcome associations, followed by hierarchical regression modeling to account for demographic and clinical variables. For each regression model, age, gender, and pain duration were loaded in the first block, followed by FABQ-W in the second block.

Next, work-related fear-avoidance was examined for association with pain intensity and function level change scores (discharge and intake) from physical therapy treatment. This was investigated in a parallel fashion as with intake scores, with simple associations first determined by Pearson's Product Moment Correlation. For each hierarchical regression model, age, gender, and pain duration were loaded in the first block, followed by FABQ-W in the second block.

\section{Results}

During the data collection period, 672 patients with musculoskeletal pain were treated at an outpatient orthopedic facility. Of these, 359 were excluded due to incomplete intake and discharge assessment measurements, and/or not completing physical therapy prior to date of data collection. Therefore, 313 eligible patients were included in the current analysis. A summary of intake characteristics by anatomical location are provided in Table 1.

\section{Aim I: gender and anatomical location of musculoskeletal pain}

Comparison of FABQ-W scores by gender for the four anatomical locations with musculoskeletal pain are illustrated in Figure 1. No significant interaction was found to exist between gender and anatomical location of musculoskeletal pain on FABQ-W scores $(P>0.01)$. A significant main effect was observed for anatomical location of musculoskeletal pain $(\mathrm{F}(3,305)=4.918, P<0.01)$. Bonferroni post hoc testing revealed a significant difference in mean FABQ-W scores for patients in the cervical $(13.36$, standard error $[\mathrm{SE}]=1.30)$ versus lower extremity $(7.51, \mathrm{SE}=0.90)$ group only. Effect sizes (Cohen's d) were observed to be small to moderate, ranging from as low as 0.09 (upper extremity versus lower extremity group) to as high as 0.60 (cervical versus lower extremity group) (Table 2). Gender was not found to be a significant main effect of work-related fear-avoidance across the four anatomical locations $(P>0.01)$ (Figure 1).

\section{Aim 2: pain intensity and function Intake scores}

Average intake pain intensity and function scores are provided in Table 3. A positive univariate relationship was found between FABQ-W scores and intake pain intensity scores for the cervical $(\mathrm{r}=0.437, P<0.01)$ and lumbar $(\mathrm{r}=0.352$, $P<0.01$ ) groups only (Table 4 ), suggesting higher pain intensity was associated with higher fear scores. Hierarchical regression analysis to further examine the association between work-related fear-avoidance and intake pain intensity is reported in Table 5. After accounting for demographic and clinical variables (age, gender, pain duration), FABQ-W scores yielded additional unique variance of $19.2 \%, 6.4 \%$, $10.0 \%$, and $2.0 \%$ for cervical, upper extremity, lumbar and lower extremity regions, respectively. Overall variance

Table I Intake characteristics by anatomical location

\begin{tabular}{lllll}
\hline Characteristic & Cervical & Upper extremity & Lumbar & Lower extremity \\
\hline $\mathrm{N}$ & 63 & 58 & 79 & 113 \\
Mean age (years) & 43.75 & 44.38 & 46.66 & 46.11 \\
Male $(\mathrm{n})$ & 18 & 22 & 30 & 45 \\
Female (n) & 45 & 36 & 49 & 68 \\
Mean pain duration (days) & 483.48 & 233.36 & 610.11 & 521.58 \\
\hline
\end{tabular}

Abbreviation: $\mathrm{N}$, number. 


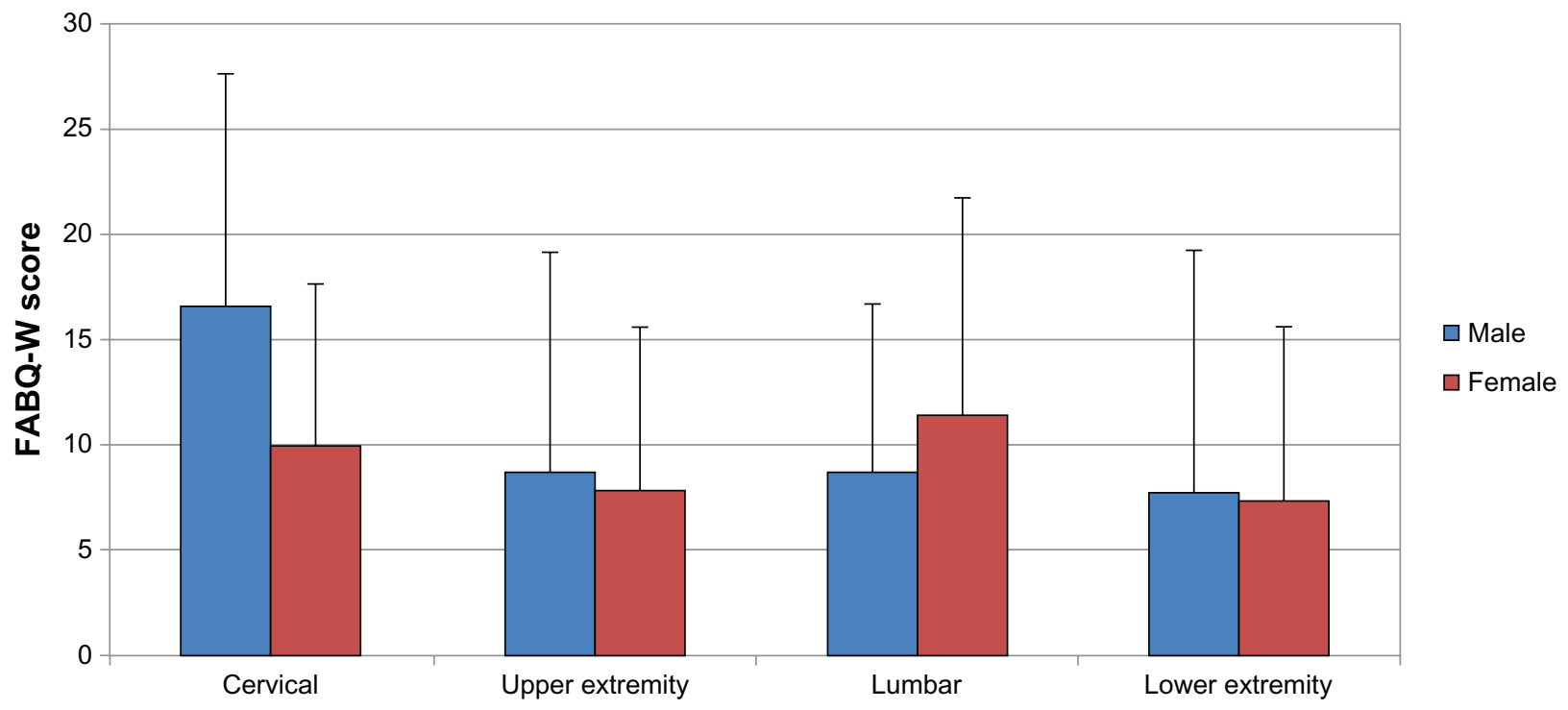

Figure I Mean raw FABQ-W scores (scale 0-42) with standard deviation; separated by anatomical location of musculoskeletal pain and split by gender. Abbreviation: FABQ-W, Fear-Avoidance Beliefs Questionnaire work subscale.

explained by the final models for intake pain intensity was $20 \%, 11 \%, 21 \%$, and $4 \%$ for the cervical, upper extremity, lumbar and lower extremity regions, respectively. In line with the correlation findings, a positive association between intake pain intensity and FABQ-W scores was found for the cervical (St Beta $=0.13, P<0.001)$ and lumbar (St Beta $=0.08$, $P<0.01)$ regions in the hierarchical regression models.

A negative relationship between FABQ-W scores and intake function level were found for all musculoskeletal pain groups (Table 4), suggesting lower function levels for patients with higher work-related fear-avoidance. For influence of work-related fear-avoidance on intake function level, additional unique variance from the FABQ-W was $4.7 \%, 8.0 \%, 2.8 \%$, and $10.3 \%$ for the cervical, upper extremity, lumbar, and lower extremity regions, respectively. Overall variance explained by the final models for intake function was $52 \%, 32 \%, 31 \%$, and $27 \%$ for cervical, upper extremity, lumbar and lower extremity regions, respectively. After controlling for demographic and clinical variables,

Table 2 Differences in mean raw FABQ-W scores and effect sizes for four anatomical locations

\begin{tabular}{llll}
\hline Group comparison & MD & ES & $P$ value \\
\hline Cervical vs upper extremity & 5.02 & 0.51 & 0.06 \\
Cervical vs lower extremity & 5.85 & 0.60 & $<0.01$ \\
Cervical vs lumbar & 3.35 & 0.34 & 0.48 \\
Upper extremity vs lumbar & 1.67 & 0.18 & 1.00 \\
Upper vs lower extremity & 0.83 & 0.09 & 1.00 \\
Lower extremity vs lumbar & 2.5 & 0.26 & 0.76 \\
\hline
\end{tabular}

Abbreviations: ES, effect size (Cohen's d); FABQ-W, Fear-Avoidance Beliefs Questionnaire work subscale; MD, mean difference. negative associations were observed for FABQ-W scores in the upper (St Beta $=-0.54, P<0.01)$ and lower extremity (St Beta $=-0.62, P<0.01)$ regions, only. The contribution of FABQ-W scores to intake function scores did not reach significance $(P>0.01)$ for the cervical and lumbar spine regions (Table 5).

\section{Change scores}

Average change in pain intensity and function scores are provided in Table 3. A positive correlation was observed for pain intensity change in the lumbar group $(\mathrm{r}=0.331, P<0.01)$, suggesting larger changes in pain for patients with low back pain and higher work-related fear-avoidance (Table 4). However, no other anatomical location had a significant association between work beliefs and change in pain $(P>0.01)$. Hierarchical regression analysis further examined influence of work-related fear-avoidance on pain intensity change scores (Table 6). Additional unique variance for FABQ-W scores was $8.4 \%, 6.3 \%, 8.5 \%$ and $0.4 \%$ for the cervical, upper extremity, lumbar, and lower extremity regions, respectively. Overall variance explained by the final models for change in pain was $10.0 \%, 10.7 \%, 14.1 \%$ and $2.8 \%$ for cervical, upper extremity, lumbar and lower extremity regions, respectively. After controlling for demographic and clinical variables, a positive association was observed for FABQ-W scores in the lumbar region $($ St Beta $=0.31, P<0.01)$ only.

For function, the only anatomical location associated with change scores was the lower extremity $(\mathrm{r}=0.335, P<0.01)$ (Table 4). This also suggests larger changes in function with higher FABQ-W scores. Hierarchical regression analysis 
Table 3 Average pain and function scores by anatomical location

\begin{tabular}{|c|c|c|c|c|c|}
\hline Variable & & Cervical & Upper extremity & Lumbar & Lower extremity \\
\hline \multirow[t]{2}{*}{ Intake pain (VAS) } & Mean & 4.47 & 3.91 & 4.13 & 3.06 \\
\hline & $\mathrm{SD}$ & 2.45 & 2.22 & 2.38 & 2.25 \\
\hline \multirow[t]{2}{*}{ Intake function (CCFOI) } & Mean & 72.86 & 71.45 & 70.78 & 72.64 \\
\hline & SD & 16.08 & $|5.6|$ & 16.06 & $18.2 \mid$ \\
\hline \multirow[t]{2}{*}{ Discharge pain (VAS) } & Mean & 1.19 & 0.67 & 1.04 & 0.69 \\
\hline & SD & 1.58 & 0.75 & 1.32 & 1.13 \\
\hline \multirow[t]{2}{*}{ Discharge function (CCFOI) } & Mean & 91.10 & 92.12 & 89.85 & 92.97 \\
\hline & $\mathrm{SD}$ & 9.73 & 9.00 & 10.63 & 10.58 \\
\hline \multirow[t]{2}{*}{ Change pain } & Mean & 3.28 & 3.24 & 3.17 & 2.37 \\
\hline & SD & 2.49 & 2.16 & 2.35 & 2.07 \\
\hline \multirow[t]{2}{*}{ Change function } & Mean & 18.78 & 20.67 & 19.06 & 20.34 \\
\hline & SD & 17.30 & 13.65 & 16.16 & 15.26 \\
\hline
\end{tabular}

Abbreviations: CCFOI, CareConnections Functional Outcomes Index; SD, standard deviation; VAS, visual analog scale.

Table 4 Univariate associations between anatomical location and pain/function measures

\begin{tabular}{lllll}
\hline FABQ-W by region & Intake pain & Change pain & Intake function & Change function \\
\hline Cervical & $0.437^{*}$ & 0.297 & $-0.523^{*}$ & 0.271 \\
Upper extremity & 0.217 & 0.214 & $-0.336^{*}$ & 0.332 \\
Lumbar & $0.352^{*}$ & $0.331^{*}$ & $-0.340^{*}$ & 0.235 \\
Lower extremity & 0.130 & 0.049 & $-0.339^{*}$ & $0.335^{*}$ \\
\hline
\end{tabular}

Note: $* P<0.01$.

Abbreviation: FABQ-W, Fear-Avoidance Beliefs Questionnaire work subscale.

Table 5 Work-related fear-avoidance contribution to intake pain intensity and functional scores by anatomical location

\begin{tabular}{|c|c|c|c|c|c|}
\hline \multirow[t]{2}{*}{ Measure } & \multicolumn{2}{|c|}{ Pain intensity } & \multirow[t]{2}{*}{ Measure } & \multicolumn{2}{|c|}{ Function } \\
\hline & B & $P$ & & B & $P$ \\
\hline & \multicolumn{2}{|c|}{$\begin{array}{l}\text { Final cervical model } \\
\left(r^{2}=0.203, P=0.01\right)\end{array}$} & & \multicolumn{2}{|c|}{$\begin{array}{l}\text { Final cervical model } \\
\left(r^{2}=0.518, P<0.01\right)\end{array}$} \\
\hline Age & 0.02 & 0.99 & Age & -0.08 & 0.40 \\
\hline Gender & 0.09 & 0.48 & Gender & 0.16 & 0.11 \\
\hline Duration & -0.08 & 0.52 & Duration & 0.16 & 0.10 \\
\hline \multirow[t]{3}{*}{ FABQ-W } & 0.46 & $<0.01$ & Pain intensity & -0.48 & $<0.0$ \\
\hline & & & FABQ-W & -0.26 & 0.02 \\
\hline & \multicolumn{3}{|c|}{$\begin{array}{l}\text { Final upper extremity model } \\
\left(r^{2}=0.106, P>0.01\right)\end{array}$} & \multicolumn{2}{|c|}{$\begin{array}{l}\text { Final upper extremity model } \\
\left(r^{2}=0.420, P<0.01\right)\end{array}$} \\
\hline Age & 0.20 & 0.14 & Age & 0.07 & 0.53 \\
\hline Gender & 0.12 & 0.37 & Gender & -0.16 & 0.14 \\
\hline Duration & -0.06 & 0.68 & Duration & 0.30 & $<0.0$ \\
\hline \multirow[t]{3}{*}{ FABQ-W } & 0.26 & 0.06 & Pain intensity & -0.43 & $<0.0$ \\
\hline & & & FABQ-W & -0.30 & 0.01 \\
\hline & \multicolumn{2}{|c|}{$\begin{array}{l}\text { Final lumbar model } \\
\left(r^{2}=0.206, P<0.01\right)\end{array}$} & & \multicolumn{2}{|c|}{$\begin{array}{l}\text { Final lumbar model } \\
\left(r^{2}=0.313, P<0.01\right)\end{array}$} \\
\hline Age & 0.16 & 0.15 & Age & -0.01 & 0.96 \\
\hline Gender & 0.17 & 0.11 & Gender & 0.08 & 0.43 \\
\hline Duration & -0.18 & 0.10 & Duration & -0.03 & 0.76 \\
\hline \multirow[t]{3}{*}{ FABQ-W } & 0.33 & $<0.01$ & Pain intensity & -0.49 & $<0.0$ \\
\hline & & & FABQ-W & -0.19 & 0.09 \\
\hline & \multicolumn{2}{|c|}{$\begin{array}{l}\text { Final lower extremity model } \\
\left(r^{2}=0.044, P>0.01\right)\end{array}$} & & \multicolumn{2}{|c|}{$\begin{array}{l}\text { Final lower extremity model } \\
\left(r^{2}=0.267, P<0.01\right)\end{array}$} \\
\hline Age & 0.01 & 0.93 & Age & -0.18 & 0.03 \\
\hline Gender & 0.11 & 0.24 & Gender & -0.02 & 0.84 \\
\hline Duration & -0.11 & 0.27 & Duration & 0.12 & 0.17 \\
\hline \multirow[t]{2}{*}{ FABQ-W } & 0.15 & 0.13 & Pain intensity & -0.32 & $<0.0$ \\
\hline & & & FABQ-W & -0.33 & $<0.0$ \\
\hline
\end{tabular}

Notes: Age, duration, FABQ-W scores, and pain intensity scores entered as continuous measures; gender coded 0 for male, I for female.

Abbreviation: FABQ-W, Fear-Avoidance Beliefs Questionnaire work subscale; B, standardized beta coefficient. 
Table 6 Work-related fear-avoidance contribution to changes in pain intensity and functional scores by anatomical location

\begin{tabular}{|c|c|c|c|c|c|}
\hline \multirow[t]{2}{*}{ Measure } & \multicolumn{2}{|c|}{ Pain intensity } & \multirow[t]{2}{*}{ Measure } & \multicolumn{2}{|c|}{ Function } \\
\hline & B & $P$ & & B & $P$ \\
\hline & \multicolumn{2}{|c|}{$\begin{array}{l}\text { Final cervical model } \\
\left(r^{2}=0.100, P>0.01\right)\end{array}$} & & \multicolumn{2}{|c|}{$\begin{array}{l}\text { Final cervical model } \\
\left(r^{2}=0.194, P>0.01\right)\end{array}$} \\
\hline Age & -0.02 & 0.86 & Age & 0.08 & 0.51 \\
\hline Gender & 0.04 & 0.77 & Gender & -0.14 & 0.29 \\
\hline Duration & -0.11 & 0.41 & Duration & -0.17 & 0.16 \\
\hline \multirow[t]{3}{*}{ FABQ-W } & 0.31 & 0.02 & Pain intensity & 0.28 & 0.04 \\
\hline & & & FABQ-W & 0.10 & 0.49 \\
\hline & \multicolumn{3}{|c|}{$\begin{array}{l}\text { Final upper extremity model } \\
\left(r^{2}=0.107, P>0.01\right)\end{array}$} & \multicolumn{2}{|c|}{$\begin{array}{l}\text { Final upper extremity model } \\
\left(r^{2}=0.442, P<0.01\right)\end{array}$} \\
\hline Age & 0.11 & 0.40 & Age & -0.24 & 0.03 \\
\hline Gender & 0.20 & 0.14 & Gender & 0.18 & 0.09 \\
\hline Duration & -0.10 & 0.46 & Duration & -0.37 & $<0.01$ \\
\hline \multirow[t]{3}{*}{ FABQ-W } & 0.26 & 0.06 & Pain intensity & 0.39 & $<0.01$ \\
\hline & & & FABQ-W & 0.30 & 0.01 \\
\hline & \multicolumn{2}{|c|}{$\begin{array}{l}\text { Final lumbar model } \\
\left(r^{2}=0.141, P>0.01\right)\end{array}$} & & \multicolumn{2}{|c|}{$\begin{array}{l}\text { Final lumbar model } \\
\left(r^{2}=0.242, P<0.01\right)\end{array}$} \\
\hline Age & 0.06 & 0.60 & Age & -0.05 & 0.64 \\
\hline Gender & 0.09 & 0.44 & Gender & -0.18 & 0.11 \\
\hline Duration & -0.16 & 0.16 & Duration & 0.05 & 0.65 \\
\hline \multirow[t]{3}{*}{ FABQ-W } & 0.31 & $<0.01$ & Pain intensity & 0.47 & $<0.01$ \\
\hline & & & FABQ-W & 0.09 & 0.42 \\
\hline & \multicolumn{2}{|c|}{$\begin{array}{l}\text { Final lower extremity model } \\
\left(r^{2}=0.028, P>0.01\right)\end{array}$} & & \multicolumn{2}{|c|}{$\begin{array}{l}\text { Final lower extremity model } \\
\left(r^{2}=0.224, P<0.01\right)\end{array}$} \\
\hline Age & 0.00 & 1.00 & Age & -0.04 & 0.68 \\
\hline Gender & 0.11 & 0.28 & Gender & 0.00 & 0.99 \\
\hline Duration & -0.11 & 0.27 & Duration & -0.13 & 0.13 \\
\hline \multirow[t]{2}{*}{ FABQ-W } & 0.06 & 0.52 & Pain intensity & 0.29 & $<0.01$ \\
\hline & & & FABQ-W & 0.31 & $<0.01$ \\
\hline
\end{tabular}

Notes: Age, duration, FABQ-W scores, and pain intensity scores entered as continuous measures; gender coded 0 for male, I for female. Abbreviation: FABQ-W, Fear-Avoidance Beliefs Questionnaire work subscale; B, standardized beta coefficient.

revealed additional unique variance of $0.7 \%, 7.8 \%, 0.7 \%$, and $9.0 \%$, cervical, upper extremity, lumbar, and lower extremity regions, respectively. Overall variance explained by the final models for change in function was $19.4 \%, 44.2 \%$, $24.2 \%$, and $22.4 \%$ for cervical, upper extremity, lumbar and lower extremity regions, respectively. After controlling for demographic and clinical variables, a positive association with change in function was observed for FABQ-W scores in the upper (St Beta $=0.30, P=0.01$ ) and lower extremity (St Beta $=0.31, P<0.01)$ regions, only.

\section{Discussion}

To the authors' knowledge, this is the first study to examine the effect of gender and anatomical location of musculoskeletal pain on work-related fear-avoidance for multiple body sites. Results indicate that work-related fear-avoidance with cervical or extremity musculoskeletal pain are of similar magnitude to that reported by patients with low back pain. This finding is consistent with an earlier study examining differences in FABQ-W scores for musculoskeletal pain in cervical versus lumbar regions, ${ }^{12}$ and suggests that the FABQ-W is an appropriate measure of work-related fear -avoidance for other musculoskeletal regions.

Gender differences in work-related fear-avoidance scores for the four anatomical locations were also examined. Previous investigation into the fear construct (using measures other than the FABQ) found higher levels observed for males with neck ${ }^{12}$ or low back pain, ${ }^{11,12}$ as well as unspecified chronic musculoskeletal pain. ${ }^{25}$ Additionally, a recent multicenter international study of Dutch and Canadian/Swedish population samples found a significant association between gender and fear of movement and/ or re-injury, with males demonstrating higher scores. ${ }^{26}$ In contrast, other psychological constructs like catastrophizing have found consistently higher reports for females. ${ }^{27-29}$ Nevertheless, the findings in the present study did not support any difference in work-related fear-avoidance reports by gender. It is important to consider that gender may not influence the effect of anatomical location on work-related fear-avoidance. 
Comparing influence of work beliefs on pain and function across anatomical locations was not directly addressed with comparisons of mean FABQ-W scores. For these purposes, associations between work-related fear-avoidance and pain intensity or function were examined across the four anatomical locations and, contrary to the authors' hypothesis, associations were not universally higher for low back pain. Work-related fear-avoidance did provide the largest variance explained for change in pain intensity for the lumbar group, which was also the only group significant for this outcome. Overall, variance explained by work-related fear-avoidance after accounting for demographics were consistently higher for models of function compared with pain intensity, which illustrates the potential importance of work beliefs on function. That said, there was an observed specificity to clinical outcomes by anatomical location after accounting for age, gender, and pain duration. Associations between work-related fear-avoidance and intake pain intensity were found only in patients with spine conditions. In contrast, associations between work-related fearavoidance and intake function were only found for patients with extremity conditions. Interestingly, these results do not parallel associations with fear of physical activity observed in the prospective cohort study of the same patient population. ${ }^{18}$ For that analysis, fear of physical activity was found to have a uniform association with pain and function across anatomical location. Comparatively, variance explained by fear of physical activity models was larger than work-related fear-avoidance models for intake scores in all but two instances (cervical model for intake pain, lower extremity model for intake function). Collectively, this may indicate that fear-avoidance is not a uniform construct and that a separate assessment is needed for fear or work and physical activity.

The reason for specificity to clinical outcomes based on anatomical location for work-related fear-avoidance can only be speculated. It is possible that in the presence of neck or low back pain, work beliefs or experiences have a stronger influence over pain intensity because of a unique influence on pain perception for spinal conditions. In other words, specific work beliefs for groups with spine pain may garner a perception that are influential to pain but not to the accompanying functional task. However, the association observed between work-related fear-avoidance and function may be indicative of a unique perceived threat to function outside of work (eg, a participant with a knee injury may relate a task to difficulty walking but not to increased pain). Another possibility may be that the type of work-related tasks performed in the cervical and lumbar groups were linked to a higher pain experience than tasks performed by the extremity groups. However, this does not explain specificity to function for the extremity groups; examination of such effects would require a more complex experimental design.

Regardless of the rationale, the lack of association between work-related fear-avoidance and function for patients with low back pain was a puzzling finding in this study. Waddell et a ${ }^{11}$ observed a strong association between work-related fear-avoidance and disability (loss of function) in the low back pain cohort used for the original FABQ study, and the authors of the present study have found similar results in their other studies. ${ }^{2-4}$ One explanation is that functional differences across anatomical locations are related to the metric used. In this study, the CCFOI was implemented instead of the Oswestry Disability Questionnaire (ODQ) that has been used in previous studies of patients with low back pain. The CCFOI has not been utilized as a functional measurement tool, despite its comprehensiveness and standardization across many treatment facilities nationally. However, the ODQ is frequently utilized in this area as a functional measurement tool for low back pain, but it is not appropriate for use in other anatomical locations. Future analysis of the CCFOI, including psychometrics and comparison to the ODQ, may shed light on whether the anatomical specificity of function is related to the measurement tool utilized. A final consideration for lack of association between work-related fear-avoidance and function in the presence of low back pain is the heterogeneity of participants. The sample in the present study included - but was not exclusive to - patients with work-related musculoskeletal injuries. It is possible that with a more specific subgroup of patients, a significant association with function may be found.

Another key finding was the direction of effect observed between work-related fear-avoidance and clinical outcome change scores. Though not a formal hypothesis, it was anticipated that findings would be similar to previous work in this area, where higher work-related fear-avoidance was linked to lower changes in pain intensity and function. ${ }^{2,4}$ This tendency acts in accordance with fear-avoidance theory, as pain-related fear may produce avoidance behaviors resulting in disability. However, for patients with low back pain, higher work-related fear-avoidance beliefs resulted in larger changes in pain intensity from intake to discharge. Similarly, for patients with upper and lower extremity pain, higher work-related fear-avoidance beliefs resulted in larger changes in function from intake to discharge. Although speculative, this discrepancy may be associated with higher capacity for change or regressions to the mean. Individuals with higher work-related fear-avoidance might have greater potential to demonstrate change compared with individuals with lower work-related 
fear-avoidance, simply because the distance between units of measurement for intake and discharge are larger.

Limitations of the current study should be considered when interpreting these results. First, work-related factors (eg, mechanism of injury, payor status, employment/return to work status) were not included in this analysis. Previous studies have reported a relationship between fear-avoidance scores and work-related factors. ${ }^{11,12,30-32}$ Another limitation was that physical therapy treatment, including education and intervention strategies for elevated fear-avoidance, were not standardized. This was intentional so as to replicate a typical outpatient orthopedic environment. However, since specific strategies were not tracked, changes or differences in approach based on level of fear-avoidance status cannot be assessed. Lastly, psychometrics of the modified FABQ-W and the CCFOI have not been directly examined. Though no problems with these measurement tools were observed, the current lack of validation remains a concern.

\section{Conclusion}

The findings of this study suggest that work-related fear-avoidance beliefs for patients with neck or extremity pain are similar to patients with low back pain. Gender was not a significant factor in amount of work-related fear-avoidance beliefs by anatomical location. For associations with clinical outcomes, work-related fear-avoidance influenced intake pain intensity in patients with spine pain but not extremity pain. Conversely, only patients with extremity pain demonstrated an influence on intake function. Contrary to fear-avoidance theory and previous work in this area, higher work-related fearavoidance in this cohort was associated with more, not less, change in pain and function for certain anatomical locations.

\section{Acknowledgement}

Publication of this article was funded in part by the University of Florida Open-Access Publishing Fund.

\section{Disclosure}

This study was exempt from University of Florida Institutional Review Board since all data were collected as part of routine clinical practice and de-identified before analysis. The authors report no conflicts of interest in relation to this paper.

\section{References}

1. Crook J, Milner R, Schultz IZ, Stringer B. Determinants of occupational disability following a low back injury: a critical review of the literature. J Occup Rehabil. 2002;12(4):277-295.

2. Fritz JM, George SZ, Delitto A. The role of fear-avoidance beliefs in acute low back pain: relationships with current and future disability and work status. Pain. 2001;94(1):7-15.
3. George SZ, Fritz JM, Bialosky JE, Donald DA. The effect of a fearavoidance-based physical therapy intervention for patients with acute low back pain: results of a randomized clinical trial. Spine (Phila Pa 1976). 2003;28(23):2551-2560.

4. George SZ, Fritz JM, Childs JD. Investigation of elevated fear-avoidance beliefs for patients with low back pain: a secondary analysis involving patients enrolled in physical therapy clinical trials. J Orthop Sports Phys Ther. 2008;38(2):50-58.

5. Vowles KE, Gross RT. Work-related beliefs about injury and physical capability for work in individuals with chronic pain. Pain. 2003;101(3):291-298.

6. Fritz JM, George SZ. Identifying psychosocial variables in patients with acute work-related low back pain: the importance of fear-avoidance beliefs. Phys Ther. 2002;82(10):973-983.

7. Holden J, Davidson M, Tam J. Can the Fear-Avoidance Beliefs Questionnaire predict work status in people with work-related musculoskeletal disorders? J Back Musculoskelet Rehabil. 2010;23(4):201-208.

8. Fordyce WE. Learning processes in pain. In: Sternbach RA. The Psychology of Pain. New York: Raven Press; 1978:49-72.

9. Lethem J, Slade PD, Troup JD, Bentley G. Outline of a Fear-Avoidance Model of exaggerated pain perception - I. Behav Res Ther. 1983;21(4): 401-408.

10. Vlaeyen JW, Kole-Snijders AM, Boeren RG, van Eek H. Fear of movement/(re)injury in chronic low back pain and its relation to behavioral performance. Pain. 1995;62(3):363-372.

11. Waddell G, Newton M, Henderson I, Somerville D, Main CJ. A Fear-Avoidance Beliefs Questionnaire (FABQ) and the role of fear-avoidance beliefs in chronic low back pain and disability. Pain. 1993;52(2):157-168.

12. George SZ, Fritz JM, Erhard RE. A comparison of fear-avoidance beliefs in patients with lumbar spine pain and cervical spine pain. Spine. 2001;26(19):2139-2145.

13. Hart DL, Werneke MW, George SZ, et al. Screening for elevated levels of fear-avoidance beliefs regarding work or physical activities in people receiving outpatient therapy. Phys Ther. 2009;89(8):770-785.

14. Cleland JA, Fritz JM, Childs JD. Psychometric properties of the Fear-Avoidance Beliefs Questionnaire and Tampa Scale of Kinesiophobia in patients with neck pain. Am J Phys Med Rehabil. 2008; 87(2):109-117.

15. Piva SR, Fitzgerald GK, Wisniewski S, Delitto A. Predictors of pain and function outcome after rehabilitation in patients with patellofemoral pain syndrome. J Rehabil Med. 2009;41(8):604-612.

16. George SZ, Fritz JM, Childs JD, Brennan GP. Sex differences in predictors of outcome in selected physical therapy interventions for acute low back pain. J Orthop Sports Phys Ther. 2006;36(6):354-363.

17. Robinson ME, Dannecker EA, George SZ, Otis J, Atchison JW, Fillingim RB. Sex differences in the associations among psychological factors and pain report: a novel psychophysical study of patients with chronic low back pain. J Pain. 2005;6(7):463-470.

18. George SZ, Stryker SE. Fear-avoidance beliefs and clinical outcomes for patients seeking outpatient physical therapy for musculoskeletal pain conditions. J Orthop Sports Phys Ther. 2011;41(4):249-259.

19. George SZ, Coronado RA, Beneciuk JM, Valencia C, Werneke MW, Hart DL. Depressive symptoms, anatomical region, and clinical outcomes for patients seeking outpatient physical therapy for musculoskeletal pain. Phys Ther. 2011;91(3):358-372.

20. Scopaz KA, Piva SR, Wisniewski S, Fitzgerald GK. Relationships of fear, anxiety, and depression with physical function in patients with knee osteoarthritis. Arch Phys Med Rehabil. 2009;90(11):1866-1873.

21. Crossley KM, Bennell KL, Cowan SM, Green S. Analysis of outcome measures for persons with patellofemoral pain: which are reliable and valid? Arch Phys Med Rehabil. 2004;85(5):815-822.

22. CareConnections.com [homepage on the Internet]. Seattle: Therapeutic Associates, Inc; 2007 [cited 2011 Apr 20]. Available from: http://www. careconnections.com/outcomes/index.aspx. Accessed April 20, 2011.

23. Schunk C, Rutt R. TAOS functional index; orthopaedic rehabilitation outcomes tool. J Rehabil Outcomes Meas. 1998;2:55-61. 
24. Butler DS, Moseley GL. Explain Pain. Adelaide: Noigroup Publications; 2003.

25. Bränström H, Fahlström M. Kinesiophobia in patients with chronic musculoskeletal pain: differences between men and women. $J$ Rehabil Med. 2008;40(5):375-380.

26. Roelofs J, van Breukelen G, Sluiter J, et al. Norming of the Tampa Scale for Kinesiophobia across pain diagnoses and various countries. Pain. 2011;152(5):1090-1095.

27. Keefe FJ, Lefebvre JC, Egert JR, Affleck G, Sullivan MJ, Caldwell DS. The relationship of gender to pain, pain behavior, and disability in osteoarthritis patients: the role of catastrophizing. Pain. 2000;87(3):325-334.

28. Edwards RR, Haythornthwaite JA, Sullivan MJ, Fillingim RB. Catastrophizing as a mediator of sex differences in pain: differential effects for daily pain versus laboratory-induced pain. Pain. 2004; 111(3):335-341.
29. Forsythe LP, Thorn B, Day M, Shelby G. Race and sex differences in primary appraisals, catastrophizing, and experimental pain outcomes. J Pain. 2011;12(5):563-572. Epub 2011 Jan 29.

30. Cleland JA, Fritz JM, Brennan GP. Predictive validity of initial fear avoidance beliefs in patients with low back pain receiving physical therapy: is the FABQ a useful screening tool for identifying patients at risk for a poor recovery? Eur Spine J. 2008;17(1):70-79.

31. Grotle M, Vøllestad NK, Veierød MB, Brox JI. Fear-avoidance beliefs and distress in relation to disability in acute and chronic low back pain. Pain. 2004;112(3):343-352.

32. Pfingsten M, Kröner-Herwig B, Leibing E, Kronshage U, Hildebrandt J. Validation of the German version of the Fear-Avoidance Beliefs Questionnaire (FABQ). Eur J Pain. 2000;4(3):259-266.

\section{Publish your work in this journal}

The Journal of Pain Research is an international, peer-reviewed, open access, online journal that welcomes laboratory and clinical findings in the fields of pain research and the prevention and management of pain. Original research, reviews, symposium reports, hypothesis formation and commentaries are all considered for publication.

\section{Dovepress}

The manuscript management system is completely online and includes a very quick and fair peer-review system, which is all easy to use. Visit http://www.dovepress.com/testimonials.php to read real quotes from published authors. 